\title{
Caligus elongatus as parasites of farmed salmonids in Ireland
}

\author{
David Jackson, Sandra Deady, Daniel Hassett \& Yvonne Leahy \\ Marine Institute, Ross House, Merchants Road, Galway, Ireland
}

Keywords: sea lice, farmed salmonids, Ireland, Caligus elongatus

\begin{abstract}
Infestation patterns of Caligus elongatus on farmed Atlantic salmon and rainbow trout were investigated at several sites along the west coast of Ireland. Parasite abundances were examined in relation to host species, farm location and season. Differences were found in the relative prevalence of infestation between salmon and rainbow trout. Caligus elongatus generally contributed more as a proportion of the total lice burden on rainbow trout than on Atlantic salmon. Evidence of possible parasite transmission from wild fish stocks was found at a number of sites where marked seasonal changes in parasite abundance were observed. A wide size distribution of adult female Caligus elongatus was found at a number of sites.
\end{abstract}

\section{Contents}

Introduction 65

Material and methods 66

Results

Discussion

References

\section{Introduction}

Caligus elongatus (Nordmann) is probably the most common species of parasitic copepod in British waters, (Kabata, 1979) if not the North Atlantic. It parasitises over eighty host species, including several commercially important species of teleost and elasmobranch. $C$. elongatus contributes to sea lice infestations in farmed salmonids throughout the North Atlantic. It has been recorded from farmed fish in Norway (Bristow and Berland, 1991), Scot- land (Wootten et al., 1982), Canada (Hogans and Trudeau, 1989b) and Ireland (Jackson and Minchin, 1992). This species has been responsible for serious epizootics on farmed salmonids in both Scotland (Wootten et al;, 1982) and Canada (Hogans and Trudeau, 1989b).

In Ireland, lice levels on farmed salmonids have been monitored since 1991 (Jackson and Minchin, 1993). From the time monitoring commenced $C$. elongatus has been recorded in low numbers on Irish salmon farms. This is in strong contrast to the experience in Canada where it was recorded as accounting for over $90 \%$ of copepods recorded in a 1988 study by Hogans and Trudeau (op. cit.). The situation in Canada has since altered and Lepeophtheirus salmonis (Kroyer) is now a serious parasite of farmed salmon in Atlantic Canada. In the autumn of 1994, the first epizootic of $L$. salmonis which required treatment was recorded (Hoganš, 1995).

The pattern of occurrence of C. elongatus on farmed salmonids in Ireland is very different from that of $L_{x}$ salmonis in a number of ways. These differences do not appear to be related to competitive exclusion by the larger and more specialist salmonid ectoparasite $L$, salmonis (Jackson and Minchin, 1992). C. elongatus is often the first parasite to occur on new farms or on recently fallowed sites (op. cit.). Ovigerous female $C$. elongatus have been found on smolts in their first summer at sea, within 6-8 weeks of transfer (Minchin and Jackson, 1993). 
Table 1. Mean abundance (mean no. of lice per fish) of Caligus elongatus on Atlantic salmon (Salmo salar) in each bay sampled from 1993 to 1997. (S.E. represents the standard error of the data)

\begin{tabular}{lcccccccccc}
\hline BAY & \multicolumn{2}{c}{1993} & \multicolumn{2}{c}{1994} & \multicolumn{2}{c}{1995} & \multicolumn{2}{c}{1996} & \multicolumn{2}{c}{1997} \\
& Mean & S.E. & Mean & S.E. & Mean & S.E. & Mean & S.E. & Mean & S.E. \\
\hline Bantry Bay & 0.52 & 0.17 & 1.18 & 0.25 & 0.60 & 0.19 & 3.83 & 1.13 & 5.00 & 1.35 \\
Kenmare Bay & 0.57 & 0.18 & 0.40 & 0.06 & 0.39 & 0.09 & 1.87 & 0.38 & 0.80 & 0.13 \\
Greatmans Bay & 0.32 & 0.12 & 0.54 & 0.22 & 2.67 & 1.37 & 0.58 & 0.32 & 0.25 & 0.15 \\
Kilkieran Bay & 0.89 & 0.21 & 0.39 & 0.06 & 0.37 & 0.05 & 0.32 & 0.04 & 0.14 & 0.02 \\
Bertraghboy Bay & 2.33 & 0.88 & 0.59 & 0.19 & 0.89 & 0.25 & 1.73 & 0.51 & 0.27 & 0.06 \\
Mannin Bay & 0.46 & 0.30 & 0.45 & 0.12 & 0.33 & 0.10 & 0.95 & 0.39 & 0.11 & 0.03 \\
Ballynakill Bay & 1.29 & 0.46 & 0.76 & 0.45 & 1.45 & 0.52 & 0.10 & 0.02 & 0.45 & 0.12 \\
Killary Harbour & 1.81 & 0.35 & 1.01 & 0.43 & 1.84 & 0.56 & 3.21 & 1.00 & 0.90 & 0.28 \\
Clew Bay & 8.53 & 2.64 & 3.07 & 2.74 & 4.17 & 1.15 & 2.03 & 0.50 & 1.60 & 0.47 \\
Bealacragher Bay & 0.01 & 0.01 & 0.07 & 0.02 & 0.04 & 0.02 & 0.29 & 0.07 & 0.06 & 0.03 \\
Donegal Bay & 1.05 & 0.30 & 0.18 & 0.03 & 0.16 & 0.02 & 0.30 & 0.04 & 0.37 & 0.06 \\
Mulroy Bay & 0.03 & 0.01 & 0.03 & 0.01 & 0.02 & 0.01 & 0.20 & 0.03 & 0.10 & 0.03 \\
Lough Swilly & 1.06 & 0.72 & 0.74 & 0.27 & 0.03 & 0.02 & 0.36 & 0.19 & 0.46 & 0.11 \\
All Bays & 1.28 & 0.20 & 0.57 & 0.05 & 0.63 & 0.07 & 0.86 & 0.09 & 0.47 & 0.05 \\
\hline
\end{tabular}

\section{Materials and methods}

The sampling methodology, the regime of annual sampling of salmonid farms in Ireland and the protocol for the handling and analysis of samples is set out in Jackson et al. (1997). Generally two cages of fish were sampled for each population of fish on site; a standard cage, which was sampled at each inspection, and another cage selected at random at each inspection. Different year classes of fish were considered as different populations, as were different species (i.e. Salmon salar, Oncorhynchus mykiss). A sample of approximately thirty fish was taken from a single cage. The fish were anaesthetised and all mobile lice were removed and preserved in alcohol. All lice remaining in the anaesthetic after the sample was processed were retained and included in the sample. All lice were identified and staged. For each sample a mean number of lice per fish in each category was obtained by dividing the number of lice recorded by the number of fish examined.

\section{Results}

The mean abundance of $C$. elongatus over the period 1993 to 1997 varied widely, both between years and from bay to bay (Table 1). There were no ob-
Table 2. Caligus elongatus expressed as a proportion of the total sea lice burden recorded on Atlantic salmon and rainbow trout.

\begin{tabular}{lll}
\hline Year & Atlantic salmon & Raìnbow trout \\
\hline 1993 & 0.14 & 0.46 \\
1994 & 0.17 & 0.47 \\
1995 & 0.24 & 0.44 \\
1996 & 0.13 & 0.25 \\
1997 & 0.08 & 0.43 \\
\hline
\end{tabular}

servable trends in the mean abundance of C. elongatus over this period. In general, C. elongatus contributed more as a proportion of the total sea lice burden on rainbow trout (Oncorhynchus mykiss) (Walbaum) than on Atlantic salmon (Salmo salar, L.) (Table 2). This held true for all of the years examined. Due to the sporadic nature of the occurrence of $C$. elongatus, similar trends were more difficult to identify at specific locations.

When examined on a monthly basis, data for Atlantic salmon and rainbow trout showed seasonal maxima in winter and/or late summer/autumn (Fig. 1). This seasonality was apparent throughout the period of the study and was more clearly exhibited on salmon than on rainbow trout.

Prevalence and abundance data were examined for a number of sites. In general they varied con- 

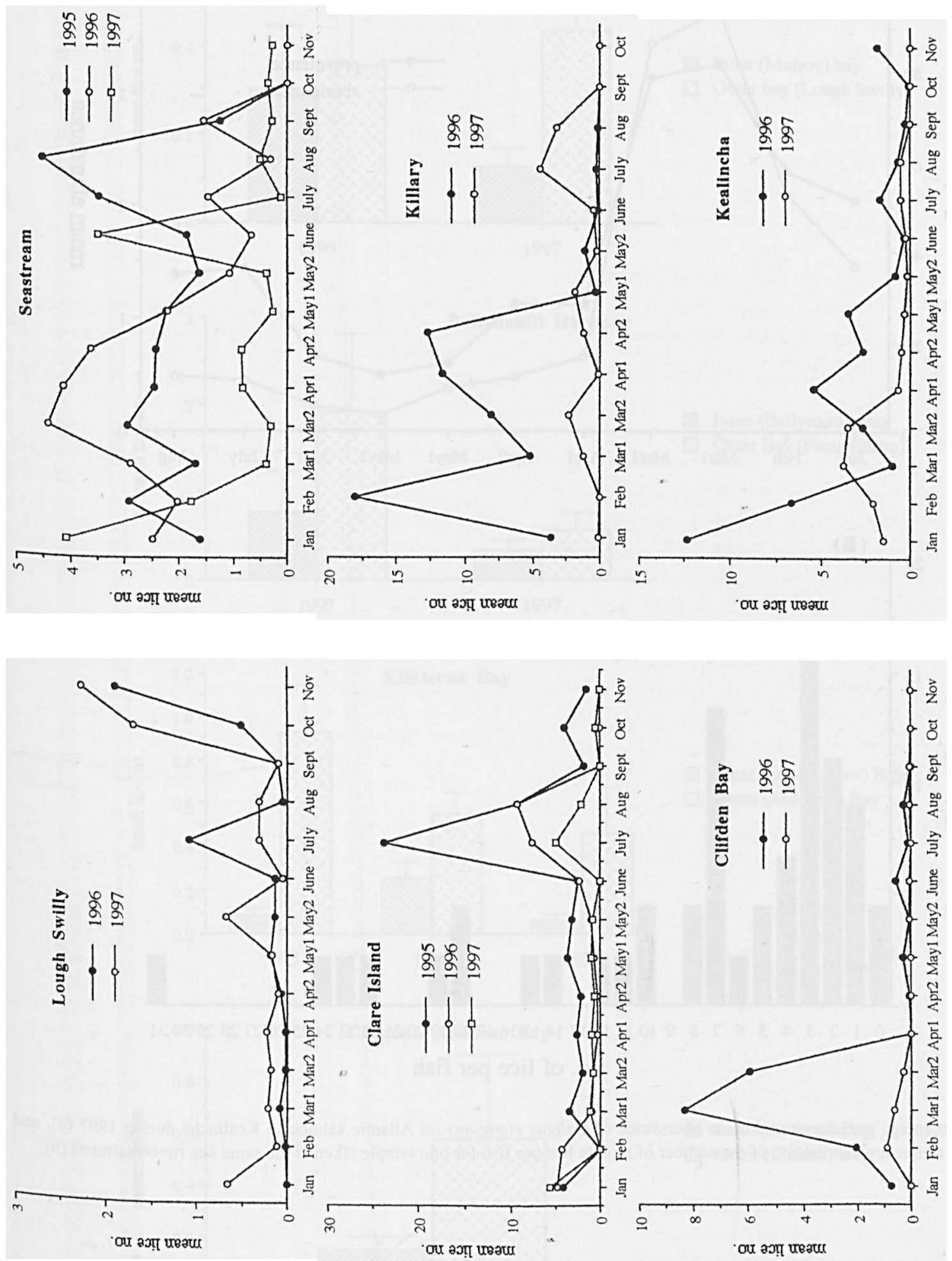

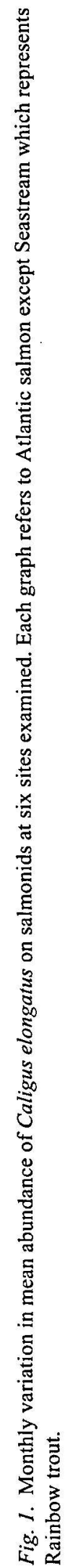



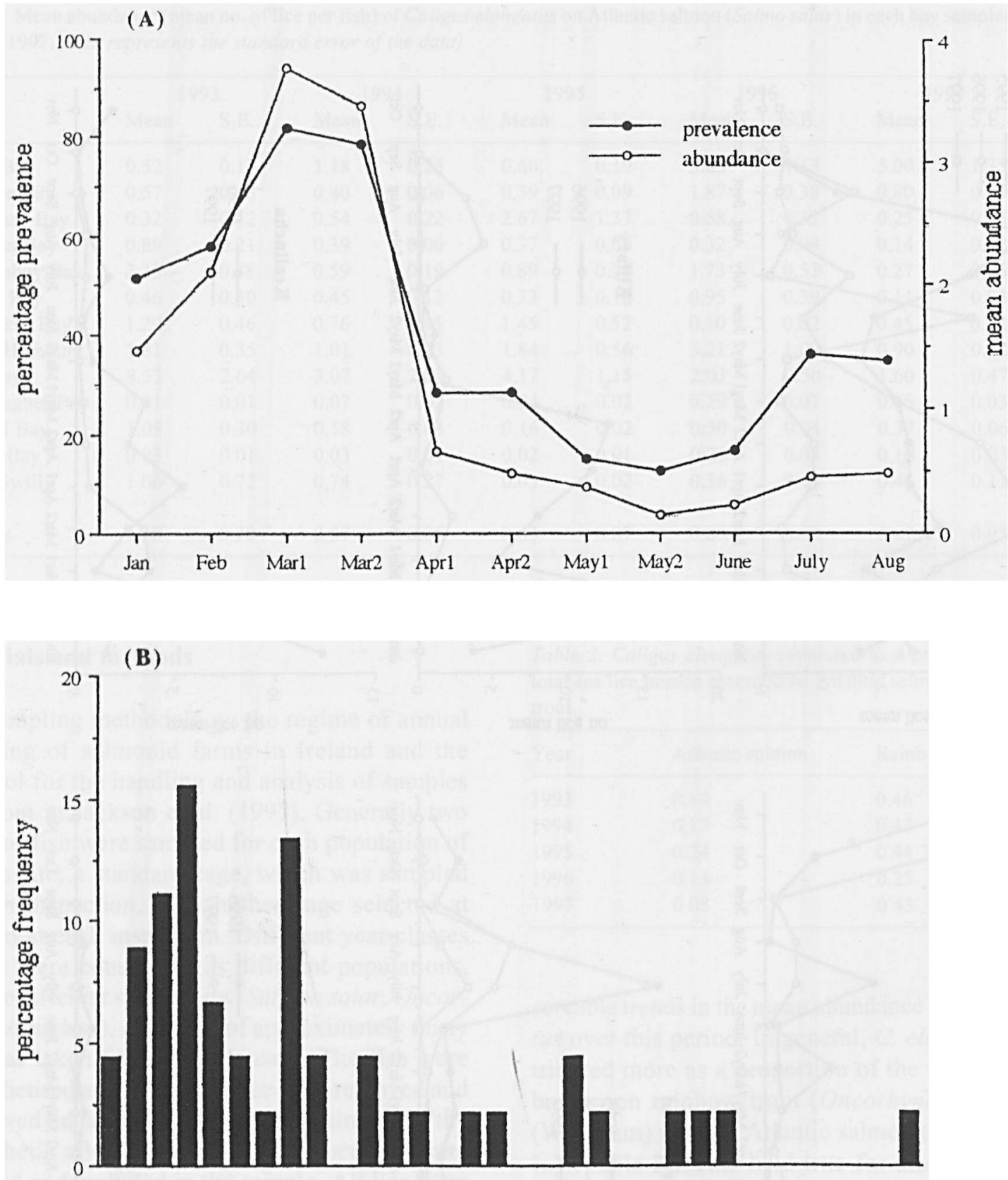

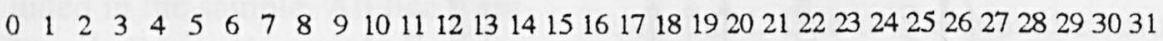

no. of lice per fish

Fig. 2. Percentage prevalance and mean abundance of Caligus elongatus on Atlantic salmon in Kealincha during 1997 (a), and percentage frequency distribution of the number of mobile lice per fish for one sample taken at the same site ( $\mathrm{n}=60$ salmon) (b).

Fig. 3. Mean abundance of Caligus elongatus on Atlantic salmon at offshore and inshore sites within the same area. 

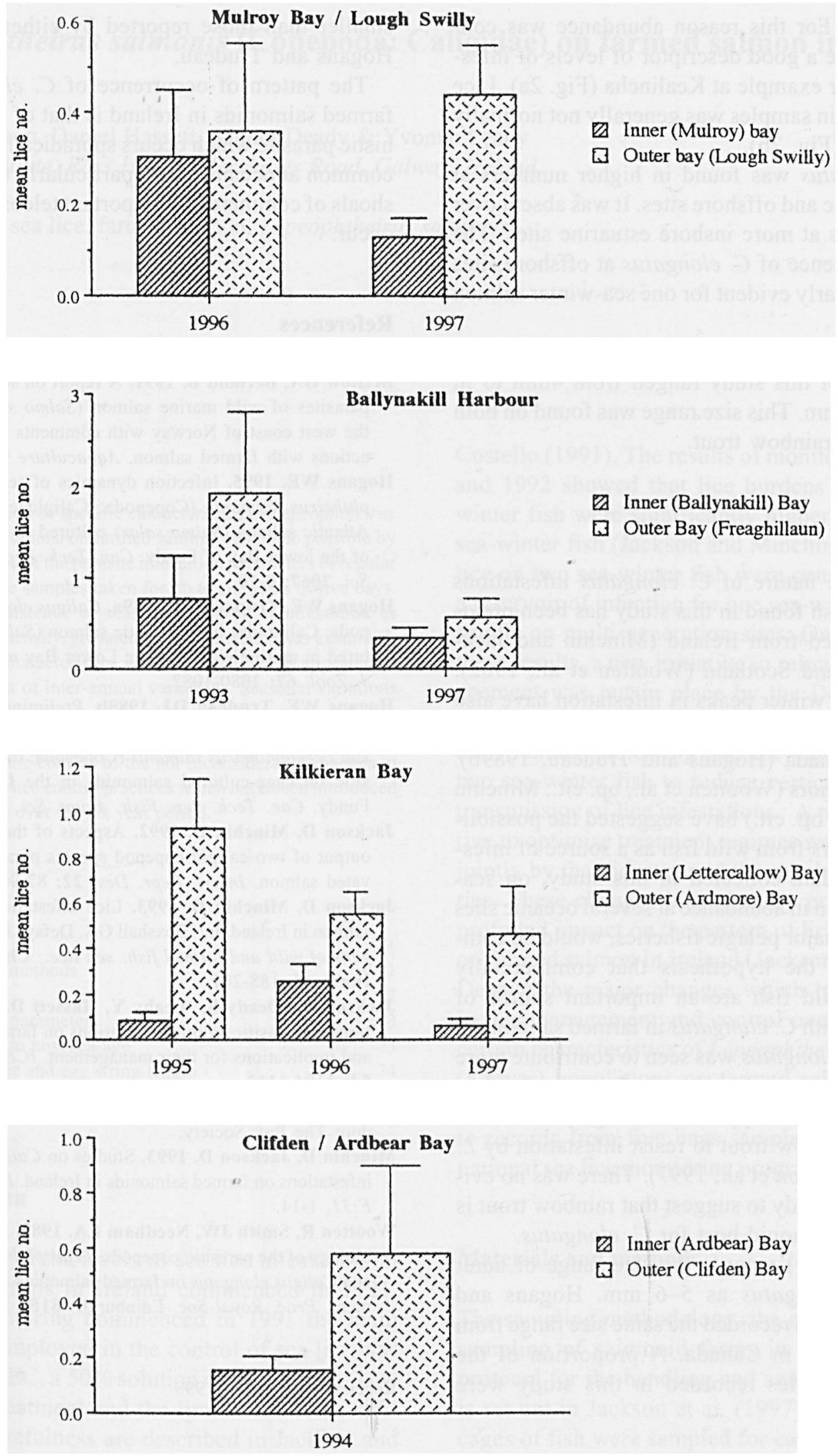
comitantly. For this reason abundance was considered to be a good descriptor of levels of infestation, as for example at Kealincha (Fig. 2a). Lice burden within samples was generally not normally distributed (Fig. 2b).

C. elongatus was found in higher numbers at more oceanic and offshore sites. It was absent over long periods at more inshore estuarine sites. The higher incidence of $C$. elongatus at offshore sites was particularly evident for one sea-winter salmon (Fig. 3).

The size of ovigerous females recorded during the course of this study ranged from $4 \mathrm{~mm}$ to in excess of $6 \mathrm{~mm}$. This size range was found on both salmon and rainbow trout.

\section{Discussion}

The variable nature of $C$. elongatus infestations on farmed fish found in this study has been previously reported from Ireland (Minchin and Jackson, 1993) and Scotland (Wootten et al., 1982). Autumn and winter peaks in infestation have also been reported from Scotland (Wootten et al., op. cit.) and Canada (Hogans and Trudeau, 1989b). Previous authors (Wootten et al., op. cit., Minchin and Jackson, op. cit.) have suggested the possibility of transfers from wild fish as a source of infestation. The data collected in this study, on seasonal variation in abundance at several oceanic sites adjacent to major pelagic fisheries, would be compatible with the hypothesis that commercially important wild fish are an important source of infestation with $C$. elongatus in farmed salmonids.

While $C$. elongatus was seen to contribute more to the total parasite burden of rainbow trout than salmon, this would appear to be largely due to the ability of rainbow trout to resist infestation by $L$. salmonis (Jackson et al., 1997). There was no evidence in this study to suggest that rainbow trout is a preferred salmonid host for $C$. elongatus.

Kabata (1979) records the size range of adult female $C$. elongatus as 5-6 mm. Hogans and Trudeau (1989a) recorded the same size range from farmed salmon in Canada. A proportion of the ovigerous females recorded in this study were smaller than those reported by either Kabata or Hogans and Trudeau.

The pattern of occurrence of C. elongatus on farmed salmonids in Ireland is that of an opportunistic parasite which occurs sporadically. It is more common at oceanic sites, particularly those where shoals of commercially important teleosts regularly occur.

\section{References}

Bristow GA, Berland B. 1991. A report on some metazoan parasites of wild marine salmon (Salmo salar L.) from the west coast of Norway with comments on their interactions with farmed salmon. Aquaculture 98: 311-318.

Hogans WE. 1995. Infection dynamics of sea lice, Lepeophtheirus salmonis (Copepoda: Caligidae) parasitic on Atlantic salmon (Salmo salar) cultured in marine waters of the lower Bay of Fundy. Can. Tech. Rep. Fish. Aquat. Sci. 2067: 0-10.

Hogans WE, Trudeau DJ. 1989a. Caligus elongatus (Copepoda: Caligoida) from Atlantic salmon (Salmo salar) cultured in marine waters of the Lower Bay of Fundy. Can. J. Zool. 67: 1080-1082.

Hogans WE, Trudeau DJ. 1989b. Prelìminary studies on the biology of sea lice, Caligus elongatus, Caligus curtus and Lepeophtheirus salmonis (Copepoda: Caligoida) parasitic on cage-cultured salmonids in the Lower Bay of Fundy. Can. Tech. Rep. Fish. Aquat. Sci. 1715: 1-14.

Jackson D, Minchin D. 1992. Aspects of the reproductive output of two caligid copepod species parasitic on cultivated salmon. Invert. Repr. Dev. 22: 87-90.

Jackson D, Minchin D. 1993. Lice infestations of farmed salmon in Ireland. In: Boxshall GA, Defaye D, eds, Pathogens of wild and farmed fish: sea lice. Chichester: Ellis Horwood, 188-201.

Jackson D, Deady S, Leahy Y, Hassett D. 1997. Variations in parasitic caligid infestations on farmed salmonids and implications for their management. ICES J. Mar. Scl. 54: 1104-1112.

Kabata Z. 1979. Parasitic Copepoda of British Fishes. London: The Ray Society.

Minchin D, Jackson D. 1993. Studies on Caligus elongatus infestations on farmed salmonids in Ireland. ICES CMI993/ $F \times 31,1-14$.

Wootten R, Smith JW, Needham EA. 1982. Aspects of the biology of the parasitic copepods, Lepeophtheirus salmonis and Caligus elongatus on farmed salmonids and their treatment. Proc. Royal Soc. Edinburgh 81B: 185-197.

Received: 18 March 1999 